\title{
Pancreatic islets from non-heart-beating donor pig: Two-layer preservation method in an in vitro porcine model
}

\author{
Maria Concetta Gioviale1, Giuseppe Damiano', Vincenzo Davide Palumbo ${ }^{1}$, Maurizio Bellavia ${ }^{1}$, Francesco \\ Cacciabaudo', Giovanni Cassata², Roberto Puleio², Roberta Altomare1, Attilio Ignazio Lo Monte ${ }^{1}$
}

${ }^{1}$ University of Palermo - School of Medicine - School of Medical Biotechnologies and Molecular Biology, Palermo - Italy

${ }^{2}$ A. Mirri Animal Health Research Institute of Sicily (IZS), Palermo - Italy

\begin{abstract}
Purpose: Pancreata from non-heart beating donors could represent an unlimited source of islets if their cell viability can be efficiently preserved during the time necessary to process the organs by the use of a better solution of preservation compared to the classic University of Wisconsin solution. The aim of this study was to determine whether it is possible to obtain functioning "alive islets" from nonheart-beating donors by comparing, on a porcine model, the classic "UW ice-store" method with a two-layer cold storage method (TLM) using oxygenated Perfluorocarbons (PFC) and UW.

Methods: Whole pancreata were harvested from 20 NHBDs female pigs with similar characteristics and preserved for $4 \mathrm{~h}$ in UW solution ( $n=10)$ or TLM (UW/PFC) solution $(n=10)$. The isolated islets were then evaluated for number, viability, purity, and insulin secretion, also estimated after 8 weeks of cryopreservation.

Results: The total number of islets obtained from isolation, and their function assayed by the insulin stimulation index, before and after cryopreservation, showed a higher value in the TLM group. No significative differences in terms of purity and viability before and after cryopreservation were found when comparing the two groups.

Conclusions: TLM solution for NHBDs porcine pancreata with cold ischemia time lower than $4 \mathrm{~h}$ offers significant advantages over UW solution storage, thereby increasing the isolation yield and isolation success rate of the pancreatic porcine islets.
\end{abstract}

KEY WORDS: Non-heart-beating donor, Pancreas procurement, Ductal injection, TLM islet isolation, Islet cryopreservation, Porcine model

Accepted: March 10, 2011

\section{INTRODUCTION}

Islet transplantation is considered the most promising way to cure type I diabetes, although several difficulties regarding their isolation, cryopreservation and the long-term functionality of the transplanted islets remain $(1,2)$. Pancreata from marginal donors could represent a valid source for isolating islets as is the case for the transplantation of other organs: non-heart-beating donors (NHBDs) are used more frequently in the world than heart-beating donors for kidney transplantation and tissue transplantation $(3,4)$. We tried to determine in a porcine model whether it is possible to obtain functioning pancreatic islets from NHBDs by comparing the classic "UW ice-store" (University of Wisconsin) method with a two-layer cold storage method (TLM) (5) using oxygenated perfluorocarbons (PFC) and the UW solution which develops a continuous supply of oxygen to the pancreas during preservation and improves islet cryopreservation. The goal is to show, in the NHBD pig, the advantages of 
the use of TLM in terms of islet viability and function even after 8 weeks of cryopreservation.

\section{MATERIALS AND METHODS}

In our study, realized in collaboration with the A. Mirri Animal Health Research Institute of Sicily (Istituto Zooprofilattico Sperimentale della Sicilia) in Palermo, Italy, we utilized whole pancreata from 20 female pigs (large white/Landrace), ranging in age from 12 to 18 months and weighing $120 \pm 40 \mathrm{~kg}$. The experimental procedure was approved by the Ethics Committee of IZS - University of Palermo and conducted in accordance with International Guidelines for Animal Experiments (6).

Following premedication using ketamine (Ketavet; Farmaceutici Gellini, Peschiera Borromeo, Italy) $10 \mathrm{mg} / \mathrm{kg}$, atropine (atropina sulfate; Monico Spa, Padua, Italy) $0.03 \mathrm{mg} /$ $\mathrm{kg}$, and diazepam (Valium; Roche, Milan, Italy) $0.4 \mathrm{mg} / \mathrm{kg}$, the anesthesia was induced with a mixture of isoflurane/ oxygen supplied by orotracheal intubation. General anesthesia was maintained by isoflurane $1 \%$ and $1.7 \%$ (Rhodia Chem SpA, Ospiate di Bollate, Italy) in 50\% oxygen supplemented with continuous infusion of fentanyl (fentanest; Pfizer, Milan, Italy) $8 \mathrm{~g} / \mathrm{kg} / \mathrm{h}$ and midazolam (Ipnovel; Roche, Milan, Italy) $0.5 \mathrm{mg} / \mathrm{kg}$ per hour. Laparotomy consisted in a midline xyphopubic incision. The animal expired from cardiac arrest shortly after exsanguination through the incision of the cava vein. To minimize operating times and, in particular, warm ischemia time, after duodenal " $\mathrm{C}$ " isolation and section through robust ties, we obtained an "en bloc" duodenum-pancreas-spleen sampling (7) that was immediately immersed in a basin containing melting ice mixed with UW solution. The operation time was defined as the time elapsed between the start of operation and removal of the pancreas. Warm ischemic time (WIT) was defined as the time elapsed between cessation of the heart-beat and placement of the pancreas into preservation solutions.

During bench surgery the pancreas was deprived of the duodenum, spleen and all lax periglandular adipose tissue. Once the Wirsung duct was isolated, it was cannulated by means of an $18 \mathrm{G}$ catheter fixed with a tie to prevent it from slipping. About $50 \mathrm{~mL}$ of UW solution (ViaSpan; BristolMyers Squibb, Latina, Italy) at $4^{\circ} \mathrm{C}$, added with dexamethasone, insulin and glutathione, were introduced through the Wirsung duct. Pancreata were divided in two groups of
10 units each. Ten pancreata (UW group) were immersed in a "bag ice storage" containing UW solution at $4^{\circ} \mathrm{C}$ for 240 minutes (8), and other 10 pancreata (TLM group) preserved in a special container for 240 minutes in a static-TLM solution (500 mL UW and $500 \mathrm{~mL}$ of preoxygenated PFC) as originally described (9-15). Oxygen was filtered through PFC for 1 hour before preservation and the container was cooled to $4^{\circ} \mathrm{C}$. This perfusion had the dual purpose of further perfusing and washing the graft. At 240 minutes, pancreatic tissue samples stored with both preservation solutions were evaluated through hematoxylin-eosin (H\&E) staining.

Possible bench dissection-induced microlesions can be remarked by loss of solution and consequently repaired through microsutures (8-0 polypropylene).

Cold ischemic time (CIT) was defined as the time elapsed between placement of the pancreas into respective preservation solutions and the start of islet isolation.

After 240 minutes of storage, islet isolation was obtained by intraductal pancreatic distension following digestion using collagenase $P$ at $3 \mathrm{mg} / \mathrm{mL}$ (Roche) according to Gray's method (16). The tissue pellet was underlayed on a discontinuous Ficoll gradient $(1108,1096,1069,1037$ g/cm³ Sigma Aldrich, Milan, Italy). After $750 \mathrm{xg}$ centrifugation at $4^{\circ} \mathrm{C}$ for 18 minutes, 1096/1069 and 1069/1037 layer interfaces were checked under a stereomicroscope and usually contained separated islets $>200 \mu \mathrm{m}$ and $<200 \mu \mathrm{m}$ diameters, respectively. To reach a high degree of purification, islets were maintained in culture in CMRL 1066 (Sigma Aldrich, Mian, Italy) supplemented with $10 \%$ FCS for two days at $37^{\circ} \mathrm{C}$, and $5 \% \mathrm{CO}_{2}$, to permit the remaining exocrine tissue to adhere to the plastic (17). An aliquot of samples containing islets was cryopreserved using DSMO (Sigma Aldrich, Milan, Italy) added at $10 \%$ in sequential stages to reduce temperature, and finally transferred into liquid nitrogen at $-196^{\circ} \mathrm{C}$. DTZ/DMSO (18) staining was used in the remaining aliquots to evaluate the optimal enzymatic digestion. The purity grade of islets and their vitality was evaluated through FDA/PI staining. Islets were counted as the total number/g of tissue and as equivalent islets/g of tissue ( $\mathrm{E} E \mathrm{q}=150 \mu \mathrm{m}$ diameter Islet Equivalent Number). Islet function was assessed by monitoring the insulin secretory response during stimulation with low and high glucose concentrations. After two days of culture, samples of $100 \mathrm{IEq}$ collected from each group were incubated for two hours with $2.8 \mathrm{mM}$ glucose in $\mathrm{CMRL} 1066$ at $37^{\circ} \mathrm{C}$ with $5 \% \mathrm{CO}_{2}$ and $100 \mathrm{IEq}$ were incubated with $25 \mathrm{mM}$ glucose in RPMI 
1640 (Sigma Aldrich, Milan, Italy) at $37^{\circ} \mathrm{C}$ and $5 \% \mathrm{CO}_{2}$. The sample supernatant was collected and insulin levels were determined by radioimmunoassay kit (19).

Cryopreserved islet aliquots, after gradual defrosting, underwent Percoll gradient (1063 gr/ $\mathrm{cm}^{3 ;}$ Sigma Aldrich) to eliminate cellular waste products about 8 weeks later. Then, the samples were maintained in culture for 24 hours at $37^{\circ} \mathrm{C}$ in CMRL 1066 with $10 \% \mathrm{FCS}$ and $5 \% \mathrm{CO}_{2}$, and finally counted again with DTZ/DMSO staining. Vitality was evaluated through FDA/PI staining while the islet function was assessed by the insulin secretory response. The stimulation index (SI) of islets before and after cryopreservation was calculated by determining the ratio of insulin released from the islet in high glucose concentration to insulin released in a low concentration. All other data were expressed as mean \pm SEM and the two groups were compared by Chi-square test. $P$ values less than 0.05 were considered significant (20).

\section{RESULTS}

In terms of donor characteristics between the two groups (UW group vs. TLM group) there were no significant differences in donor age, weight, pancreas weight, warm ischemia time (WIT) or cold ischemia time (CIT), and cryopreservation time (CT) (Tab. I). The total number of islets was significantly higher in the TLM group (see Tab. I), before and after cryopreservation $(3570 \pm 147$ in UW group vs. $5620 \pm 203$ in the TLM group, and $2676 \pm 205$ in the UW group vs. $4776 \pm 234$ in the TLM group; $p<0.0001$ ); the IEq/ gr was significantly higher in the TLM group, before and after cryopreservation $(3350 \pm 176$ in the UW group vs. $5520 \pm 203$ in the TLM group, $2462 \pm 139$ in the UW group vs. $4692 \pm 173$ in the TLM group; $p<0.0001$ assessed by Chi-square test). The purity and viability, before and after cryopresevation, did not differ significantly (purity of $75 \pm 1.2$ in the UW group vs. $77 \pm 1.77$ in the TLM group before cryopreservation, and $72 \pm 1.4$ in the UW group vs. $74 \pm 1.4$ in the TLM group; $p=$ not significant (n.s.); viability of $83 \pm 1.4$ in the UW group vs. $88 \pm 1.8$ in the TLM group before cryopreservation, $74 \pm 1.2$ in the UW group vs. $84 \pm 1.3$ in the TLM group after cryopreservation; $p=n . s$. assessed by Student's t test). The insulin secretory response during stimulation with low and high glucose concentration, before and after cryopreservation, was significantly higher in the TLM group $(2.05 \pm 0.13$ in the UW group vs. $2.5 \pm 0.16$ in the TLM group, $1.78 \pm 0.14$ in the UW group vs. $2.40 \pm 0.23$ in the TLM group; $p<0.05$ assessed by Chi-square test as shown in Tab. I). The results are depicted in Figure1. Pan-

TABLE I - DONOR CHARACTERISTICS AND RESULTS OF THE ISOLATION

\begin{tabular}{|c|c|c|c|}
\hline Data & UW & TLM & $\mathrm{P}$ \\
\hline Number of pancreas & 10 & 10 & ns \\
\hline Age (months) (range) & $12-18$ & $12-18$ & ns \\
\hline Weight $\mathrm{Kg}($ mean \pm SEM) & $120 \pm 40$ & $120 \pm 40$ & ns \\
\hline Pancreas Weight gr (mean \pm SEM) & $81 \pm 8$ & $85 \pm 9$ & ns \\
\hline WIT (min) (mean \pm SEM) & $15.6 \pm 0.3$ & $14.09 \pm 0.4$ & ns \\
\hline CIT (h) (mean \pm SEM) & $4 \pm 0.2$ & $3.9 \pm 0.3$ & ns \\
\hline CT $(\mathrm{w})($ mean \pm SEM) & $8 \pm 1$ & $8 \pm 1$ & ns \\
\hline $\mathrm{TNI} / \mathrm{g}($ mean $\pm \mathrm{SEM})$ & $3570 \pm 147.66$ & $5620 \pm 203.84$ & $<.0001$ \\
\hline TNI/g (mean \pm SEM) after cryopreservation & $2676 \pm 205.27$ & $4776 \pm 234.89$ & $<.0001$ \\
\hline $\mathrm{IEq} / \mathrm{g}($ mean $\pm \mathrm{SEM})$ & $3550 \pm 176.84$ & $5520 \pm 203.88$ & $<.0001$ \\
\hline IEq/g (mean \pm SEM) after cryopreservation & $2462 \pm 139.71$ & $4692 \pm 173.99$ & $<.0001$ \\
\hline Recovery rate after cryopreservation & 0.66 & 0.86 & - \\
\hline Purity $(\%)($ mean \pm SEM) & $75 \pm 1.29$ & $77 \pm 1.74$ & ns \\
\hline Purity (\%) (mean \pm SEM) after cryopreservation & $72 \pm 1.44$ & $74,1 \pm 1.45$ & ns \\
\hline Viability $(\%)($ mean \pm SEM) & $83 \pm 1.49$ & $88 \pm 1.85$ & ns \\
\hline Viability (\%) (mean \pm SEM) after cryopreservation & $74 \pm 1.29$ & $84 \pm 1.39$ & ns \\
\hline $\mathrm{SI}(\mathrm{mean} \pm \mathrm{SEM})$ & $2.05 \pm 0.13$ & $2.5 \pm 0.16$ & $<0.05$ \\
\hline SI (mean \pm SEM) after cryopreservation & $1.78 \pm 0.14$ & $2.40 \pm 0.23$ & $<0.05$ \\
\hline
\end{tabular}

UW = University of Wisconsin Solution; TLM, Two Layer Metod (UW/PFC solution); WIT = Warm Ischemia Time; CIT = Cold Ischemia Time; CT = Cryopreservation time; TNI = Total Number of Islets/gr; IEq/g = Islet Equivalent/g; SI = Insulin Stimulation Index: ns = not significant. 


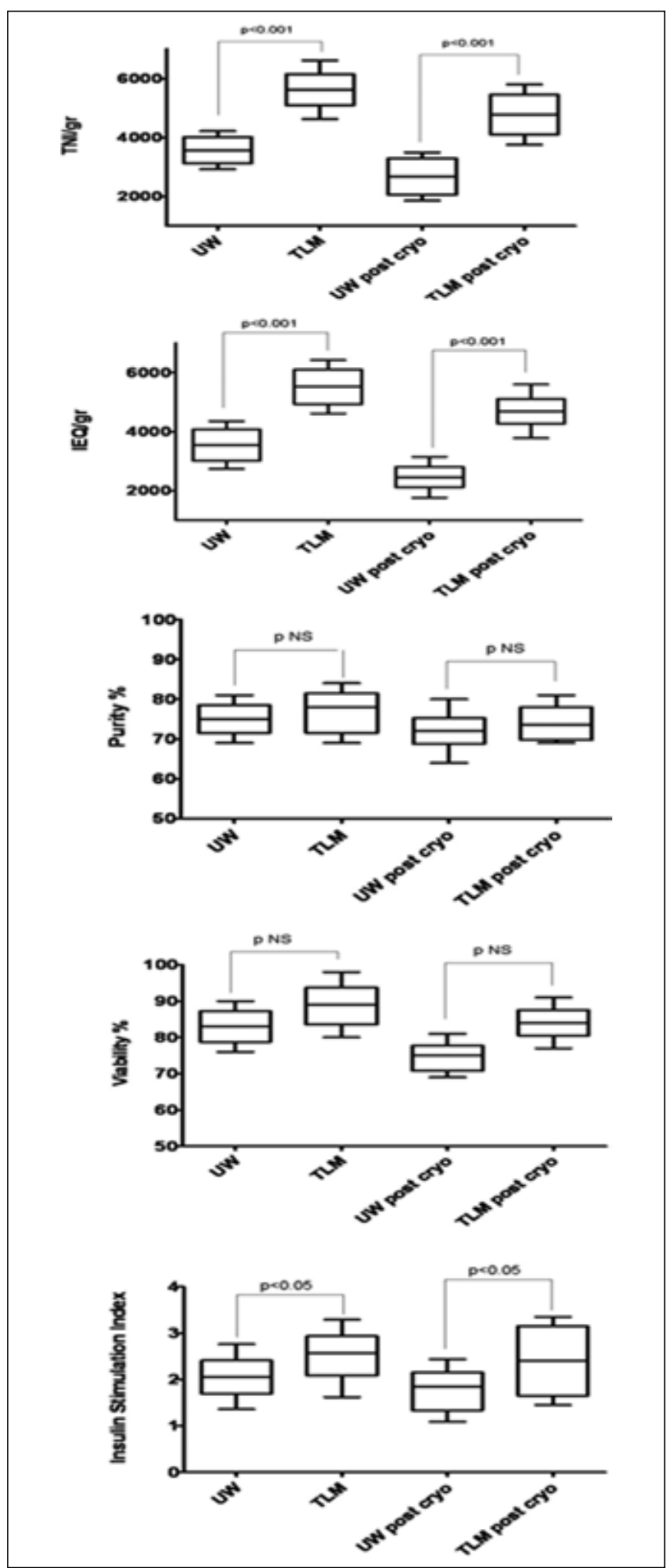

Fig. 1 - Whisker-and-box plot showing: Total Number of Islets (TNI)/g; Islet Equivalent (IEq)/g; Purity, Viability, and Insulin Stimulation Index with UW solution and TLM solution.
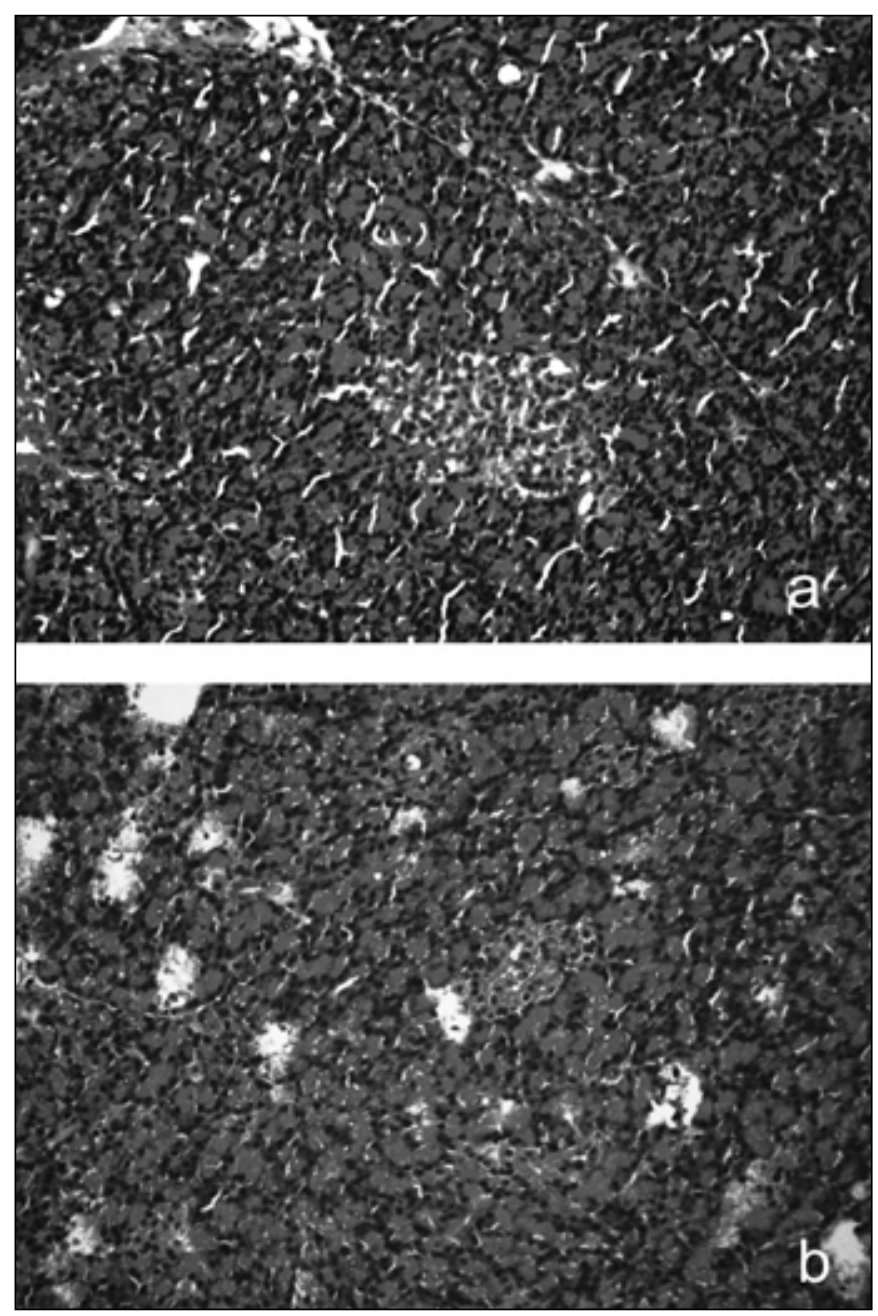

Fig. 2 - Pancreatic tissue section (H\&E staining 20x) after preservation in UW solution (a) and TLM solution (b).

creatic tissue sections after 240 minutes of preservation are shown in Figure 2. Figure 3 shows the islets collected after the preservation.

\section{DISCUSSION}

Pancreata harvested from NHBD pigs suffer many injuries due to warm ischemia after donor cross-clamping and cold ischemic storage in UW solution. The reduced success of subsequent islet isolation, therefore, depends on many factors. Using an animal model, we demonstrated in vitro the ability of TLM to reduce cold ischemic injury and 


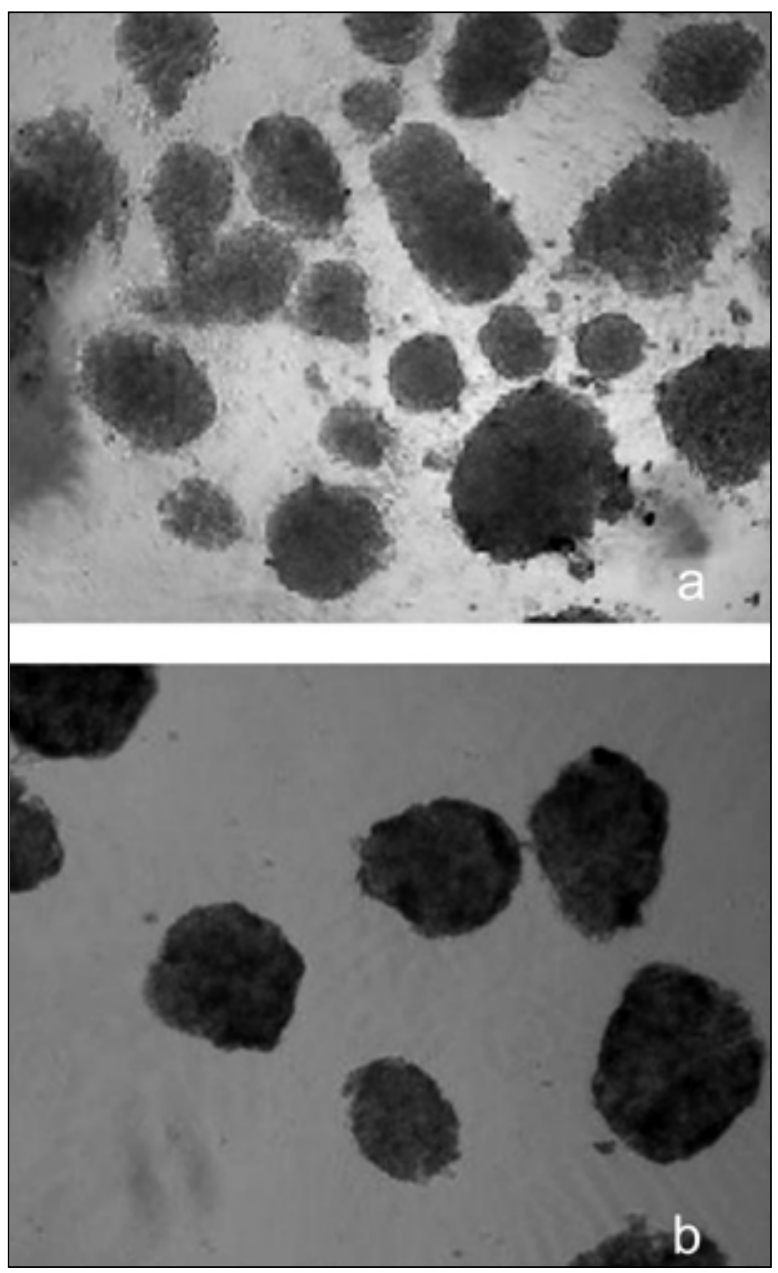

Fig. 3 - Islets isolated after 240 minutes (DTZ staining) of preservation in UW solution (a) and TLM solution (b).

increase the number and quality of active islets that are isolated from pancreata after preservation, and its ability to prolong $\beta$-cell viability even after cryopreservation.

Pancreata are usually preserved in UW solution. The use of TLM could improve islet isolation efficacy even after cryopreservation, probably thanks to the PFC contained in the solution. In fact with TLM, the pancreas is directly oxygenated by PFC during preservation and probably maintains a high level of adenosine triphosphate (ATP) in tissues, contributing to maintainance of cellular integrity and the retention of parenchymal and non-parenchymal viability, as shown by H\&E staining. In a rodent model, the TLM had a $100 \%$ success rate after 6 hours of cold preservation as compared with $50 \%$ after UW preservation (21).

Two recent papers $(22,23)$ reached different results in terms of the beneficial effect of TLM on human islet isola- tion and transplantation. In these retrospective studies, no advantages were found using TLM rather than UW during pancreas procurement from human brain-dead donors. This stands in contrast with the beneficial effect of TLM in pancreas procurement described in the literature by other authors. A first hypothesis to explain these poor results compared to the present study could be related to a suboptimal pancreas procurement, handling and packaging technique, since the cited papers are based on clinical studies and not on an experimental study model. We applied the TLM method in its original description (9-15) and a standardized technique for pancreas procurement from NHBD pigs (7) setting the CIT to 4 hours. The beneficial effect of TLM on pancreas islets procurement in our study was confirmed by the results obtained from cryopreserved islets.

Another cause explaining the contrasting results could be due to the larger thickness of the human pancreas compared to the porcine one, resulting in a minor oxygenation of the pancreatic tissue. They may also possibly be caused by a minor ischemic tolerance of human pancreas compared to the porcine pancreas. The animal model of our study is standardized for weight and age. This may be an important donor variable capable of affecting the penetration of oxygen through periglandular fat tissue.

Moreover, it is possible to assume that the pancreas procurement from a non-heart-beating model could lead to a preconditioning mechanism with induction of heat shock proteins during preservation capable of increasing the cell resistance after reperfusion damage, by providing an anti-reperfusion or cell repair property. This mechanism could be reinforced by the known effect of TLM on canine pancreas grafts to continuously generate ATP for up to 96 hours (24).

Nevertheless our results are still lacking the experimental evidence of in vivo islet function.

\section{CONCLUSIONS}

Our experiments demonstrated the advantage of the TLM over the UW solution use for short-term storage of the porcine NHBD pancreas. The TLM had more efficient islet isolation with higher islet yield. Although porcine donor characteristics were statistically similar in both groups, we think that one important factor that might have influenced our results was the use of the TLM and, in particular, the 
presence of PFC in the solution. Our study is limited by the fact that the results are based primarily on in vitro cellular function after 48 hours of culture. We were not able to evaluate the cellular function of the isolated islets in the animal model but only their in vitro function after 8 weeks of cryopreservation. Based on these results, it follows that TLM preservation leads to improved islet isolation and transplantation from pancreata from optimal or marginal donors after both short and prolonged storage $(25,26)$. The results obtained from our study on a porcine model suggest that TLM is a candidate solution to improve isolation of functioning islets harvested from the porcine NHBD pancreas, even with longer cold ischemia times.
Conflict of interest statement: The authors state that they have no proprietary interest.

Address for correspondence:

Attilio Ignazio Lo Monte

Associate Professor of Surgery

Department of General Surgery and Organ Transplantation (GEN.UR.T.O.)

University of Palermo - School of Medicine

Via del Vespro, 129

90127 Palermo, Italy

e-mail: ailomonte@unipa.it

\section{REFERENCES}

1. Liu EH, Digon BJ III, Hirshberg B, et al. Pancreatic beta cell function persists in many patients with chronic type 1 diabetes, but is not dramatically improved by prolonged immunosuppression and euglycaemia from a beta cell allograft. Diabetologia 2009; 52 (7): 1369-80. Medline. doi:10.1007/ s00125-009-1342-7

2. Ikemoto $T$, Noguchi $H$, Shimoda $M$, et al. Islet cell transplantation for the treatment of type 1 diabetes in the USA. J Hepatobiliary Pancreat Surg 2009; 16 (2): 118-23. Medline. doi:10.1007/s00534-008-0019-9

3. Brook NR, White SA, Waller JR, Veitch PS, Nicholson ML. Non-heart beating donor kidneys with delayed graft function have superior graft survival compared with conventional heart-beating donor kidneys that develop delayed graft function. Am J Transplant 2003; 3 (5): 614-8. Medline. doi:10.1034/j.1600-6143.2003.00113.x

4. Markmann JF, Deng S, Desai NM, et al. The use of nonheart-beating donors for isolated pancreatic islet transplantation. Transplantation 2003; 75 (9): 1423-9. Medline. doi:10.1097/01.TP.0000061119.32575.F4

5. Matsumoto S, Qualley SA, Goel S, et al. Effect of the two-layer (University of Wisconsin solution-perfluorochemical plus O2) method of pancreas preservation on human islet isolation, as assessed by the Edmonton Isolation Protocol. Transplantation 2002; 74 (10): 1414-9. Medline. doi:10.1097/00007890200211270-00013

6. Demers G, Griffin G, De Vroey G, Haywood JR, Zurlo J, Bedard M. Harmonization of animal care and use guidance. Science 2006; 312 (5): 700-1. Medline. doi:10.1126/science. 1124036
7. Gioviale MC, Damiano G, Montalto G, Buscemi G, Romano $\mathrm{M}$, Lo Monte Al. Isolation and culture of $\beta$-like cells from porcine Wirsung duct. Transplant Proc 2009; 41 (4): 1363-6. Medline. doi:10.1016/j.transproceed.2009.02.062

8. Stiegler P, Stadlbauer V, Hackl F, et al. Ductal injection of University of Wisconsin solution prior to pancreas preservation prevents oxidative cell damage. Transplant Proc 2009; 41 (9): 3628-31. Medline. doi:10.1016/j.transproceed.2009.06.230

9. Matsumoto S, Kuroda Y. Perfluorocarbon for organ preservation before transplantation. Transplantation 2002; 74 (12): 1804-9. Medline. doi:10.1097/00007890-200212270-00030

10. Matsumoto S, Kuroda $Y$, Hamano M, et al. Direct evidence of pancreatic tissue oxygenation during preservation by the two-layer method. Transplantation 1996; 62 (11): 1667-70. Medline. doi:10.1097/00007890-199612150-00023

11. Kuroda Y, Morita A, Fujino Y, Tanioka Y, Ku Y, Saitoh Y. Successful extended preservation of ischemically damaged pancreas by the two-layer (University of Wisconsin solution/ perfluorochemical) cold storage method. Transplantation 1993; 56 (5): 1087-90. Medline. doi:10.1097/00007890199311000-00007

12. Matsumoto S, Rigley TH, Qualley SA, et al. Efficacy of the oxygen-charged static two-layer method for short-term pancreas preservation and islet isolation from nonhuman primate and human pancreata. Cell Transplant 2002; 11 (8): 769-77. Medline.

13. Zhang G, Matsumoto S, Newman H, et al. Improved islets yield and quality from clinical grade pancreata preserved by the two-layer method. Cell Tissue Bank 2006; 7 (3): 195-201. Medline. doi:10.1007/s10561-006-0002-0

14. Noguchi H, Levi MF, Kobayashi N, et al. Pancreas Preservation by the Two-Layer Method: Does it Have a Beneficial 
Effect Compared With Simple Preservation in University of Wisconsin Solution? Cell Transplant 2009; 18 (5): 497-503. Medline.

15. Matsumoto S, Kandaswamy R, Sutherland DE, et al. Clinical application of the two-layer (University of Wisconsin solution/perfluorochemical plus O2) method of pancreas preservation before transplantation. Transplantation 2000; 70 (5): 771-4. Medline. doi:10.1097/00007890-200009150-00010

16. Gray DW, McShane P, Grant A, Morris PJ. A method for isolation of islets of Langerhans from the human pancreas. Diabetes 1984; 33 (11): 1055-61. Medline. doi:10.2337/diabetes.33.11.1055

17. Qi M, Barbaro B, Wang S, Wang Y, Hansen M, Oberholzer J. Human pancreatic islet isolation: Part II: purification and culture of human islets. J Vis Exp 2009; 26 (27) pii: 1125. doi: 10.3791/1125.

18. Fiedor P, Sung RS, Goodman ER, et al. Efficacy and safety of dithizone in staining of islet cell transplants. Transplant Proc 1995; 27 (6): 2984. Medline.

19. Takahashi T, Tanioka Y, Matsuda T, et al. Impact of the twolayer method on the quality of isolated pancreatic islets. Hepatogastroenterology 2006; 53 (68): 179-82. Medline.

20. Warnock GL, Gray DW, McShane P, Peters M, Morris PJ. Survival of cryopreserved isolated adult human pancreatic islets of Langerhans. Transplantation 1987; 44 (1): 75-82 Medline. doi:10.1097/00007890-198707000-00017
21. Tsujimura T, Kuroda Y, Avila JG, et al. Influence of pancreas preservation on human islet isolation outcomes: impact of the two-layer method. Transplantation 2004; 15 (78): 96100. doi:10.1097/01.TP.0000133515.37892.D5

22. Kin T, Mirbolooki M, Salehi P, et al. Islets isolation and transplantation outcomes of pancreas preserved with University of Wisconsin solution versus Two-layer method using preoxygenated Perfluorocarbon. Transplantation 2006; 82 (10): 1286-90 Medline. doi:10.1097/01.tp.0000244347.61060.af

23. Caballero-Corbalán J, Eich $\mathrm{T}$, Lundgren $\mathrm{T}$, et al. No beneficial effect of two-layer storage on human islets isolation and transplantation. Transplantation 2007; 84 (7): 864-9 Medline. doi:10.1097/01.tp.0000284584.60600.ab

24. Fujino $Y$, Kuroda $Y$, Suzuki $Y$, et al. Preservation of canine pancreas for 96 hours by a modified two-layer (UW solution/perfluorochemical) cold storage method. Transplantation 1991; 51 (5): 1133-5. Medline. doi:10.1097/00007890199105000-00044

25. Tsujimura T, Kuroda Y, Churchill TA, et al. Short-term storage of the ischemically damaged human pancreas by the two-layer method prior to islet isolation. Cell Transplant 2004; 13 (1): 67-73. Medline.

26. Ricordi C, Fraker C, Szust J, et al. Improved human islet isolation outcome from marginal donors following addition of oxygenated perfluorocarbon to the cold-storage solution. Transplantation 2003; 75 (9): 1524-7. 
Copyright of International Journal of Artificial Organs is the property of Wichtig Editore and its content may not be copied or emailed to multiple sites or posted to a listserv without the copyright holder's express written permission. However, users may print, download, or email articles for individual use. 